\title{
Falta de competencia del Tribunal Arbitral como causal de nulidad del laudo*
}

\author{
Valentina Centeno Arteaga** \\ Ana Belén Morales Solís*** \\ Romina Isabel Sánchez Romero ${ }^{* * * *}$ \\ Recibido/Received: 06/07/2018 \\ Aceptado/Accepted: 23/07/2018
}

Sumario: 1. Introducción. 2. La acción de nulidad y su finalidad. 3. Las causales de nulidad de laudo arbitral en el Ecuador. 4. Los criterios de competencia en un proceso arbitral. 4.1 Competencia ratione materiae. 4.2 Competencia ratione personae. 4.3 Competencia ratione voluntatis. 5 . La incompetencia como causal de nulidad del laudo en el derecho comparado. 5.1 Breve análisis del caso colombiano. 5.2 La incompetencia como causal en Chile. 6. ¿Se requiere la causal de nulidad por falta de competencia del tribunal arbitral en el Ecuador? 7. Obstáculos de la causal por falta de competencia en la acción de nulidad. 8. Conclusiones.

Palabras clave: Acción de nulidad, laudo, debido proceso, competencia, causales.

* $\quad$ Este trabajo fue uno de los ganadores del concurso de ensayos escritos realizado en el marco del curso de Procesos Arbitrales, dictado por Javier Jaramillo Troya, Profesor de la Universidad San Francisco de Quito.

** Estudiante de pregrado del Colegio de Jurisprudencia de la Universidad San Francisco de Quito. Correo electrónico: valen_centeno@hotmail.es

*** Estudiante de pregrado del Colegio de Jurisprudencia de la Universidad San Francisco de Quito. Correo electrónico: anabelenmcap@gmail.com

**** Estudiante de pregrado del Colegio de Jurisprudencia de la Universidad San Francisco de Quito. Correo electrónico: romiisanz96@gmail.com

V. Centeno, A. Morales, R. I. SÁnchez, "Falta de competencia del Tribunal Arbitral como causal de nulidad del laudo", Revista Ecuatoriana de Arbitraje, No. 9, 2017. 
KeYwords: Action of nullity, award, due process, competence, causes.

RESUMEN: La acción de nulidad del laudo arbitral protege el derecho al debido proceso, esto incluye el derecho a ser juzgado por un juez competente. Las partes tienen la facultad de pedir la revisión de la competencia del tribunal arbitral en sede judicial. Al analizar la competencia del árbitro se deben aplicar tres criterios: ratione materiae, ratione personae, ratione voluntatis. Sin embargo, la Ley de Arbitraje y Mediación solo se pronuncia sobre la falta de competencia del árbitro por materia no sometida a arbitraje.

Este artículo propone analizar la incorporación de una causal de nulidad expresa por la falta de competencia del árbitro que abarque los tres criterios antes mencionados. Se analizará la utilidad de dicha causal y los obstáculos en su implementación.

ABSTRACT: The annulment action of the arbitral award protects the right to due process, this includes the right to be judge by a competent authority. The parties have the power to request the review of the competence of the arbitral tribunal in court. When analyzing the arbitrator's competence, three criteria may be applied: ratione materiae, ratione personae, ratione voluntatis. However, the Arbitration and Mediation Law only pronounces on the arbitrator's lack of competence in matters not submitted to arbitration.

This article refers to the incorporation of a ground of nullity expressed by the lack of competence of the arbitrator, which covers the three criteria mentioned above. The usefulness of the causal and the obstacles in its implementation are also analyzed. 


\section{INTRODUCCIÓN}

Ha trascurrido alrededor de veintiún años de la promulgación de la Ley de Arbitraje y Mediación (en adelante, LAM) ${ }^{1}$. Ante varias incertidumbres que la norma genera, no cabe duda que se requiere una reforma.

La acción de nulidad de laudo arbitral ha sido uno de los puntos más controvertidos de la LAM; no sólo por los errores que contiene, sino también por omisiones. Vista la importancia que tiene la acción de nulidad como un mecanismo para salvaguardar garantías básicas del debido proceso ${ }^{2}$, se debe analizar a profundidad las necesidades que deberían considerarse ante una eventual reforma. Así, la omisión de la causal de incompetencia del tribunal como causal de nulidad es uno de los elementos que requiere la atención del legislador.

El objetivo de este estudio es determinar la necesidad de incorporar la incompetencia del tribunal como una causal de anulación del laudo arbitral en la LAM. Para ello, se analizará: (i) los fines de la acción de nulidad, (ii) la ambigüedad de los criterios para determinar la competencia de un tribunal arbitral, (iii) la causal de incompetencia en el derecho comparado y, finalmente, (iv) la necesidad y los obstáculos de la inclusión de una nueva causal en el sistema jurídico ecuatoriano.

\section{LA ACCIÓN DE NULIDAD Y SU FINALIDAD}

La esencia del arbitraje es su carácter privado, pues emana de la voluntad de dos o más partes de someter una controversia a jurisdicción arbitral ${ }^{3}$. A pesar de ser de naturaleza privada, el arbitraje es un proceso de administración justicia ${ }^{4}$. Por esta razón,

1. Ley de Arbitraje y Mediación (LAM), RO No. 145, 4/9/1997.

2. D. Barrios de Angelis, El Juicio Arbitral, Universidad de Montevideo, 1956, p. 297.

3. J. FERNÁNDEZ, "Arbitraje y Jurisdicción: una interacción necesaria para la realización de la justicia", Derecho privado y Constitución, No. 19, 2005, p. 56.

4. Código Orgánico de la Función Judicial, Art. 7, RO No. 544, 20/10/2008. 
es un mecanismo que está sujeto a regulaciones mínimas para garantizar principios que emanan de la Constitución y la ley ${ }^{5}$.

La acción de nulidad no está encaminada a corregir errores in judicando del laudo, sino irregularidades de la actividad exclusivamente procesal; es decir, errores in procedendo ${ }^{6}$. Por ello, esta acción sólo se propone una vez que el laudo ha causado ejecutoría ${ }^{7}$.

La actuación de los árbitros deberá respetar principios y garantías fundamentales del proceso. Como menciona CORONEL, "[1]as normas del debido proceso [...] deben ser respetadas en el arbitraje, al igual que en todo proceso y en todas las etapas del procedimiento" ${ }^{\prime \prime}$. De esta manera, la presente investigación se enfocará en dos garantías del debido proceso que deben ser respetadas por el árbitro: el derecho al doble conforme y el derecho a ser juzgado por un juez competente.

La Constitución de la República del Ecuador (en adelante, Constitución) en su artículo 76, numeral 7 literal m) reconoce el derecho a "[r]ecurrir el fallo o resolución en todos los procedimientos en los que se decida sobre sus derechos" ${ }^{\prime \prime}$. Es decir, el derecho al doble conforme permite que la decisión sea revisada por un órgano superior para otorgarle mayor legitimidad, seguridad y tutela ${ }^{10}$. Bajo esta noción, la acción de nulidad es una expresión amplia del debido proceso. Ello en virtud que permite a las partes impugnar un laudo, en un procedimiento autónomo, si se verifican ciertas causales previamente establecidas ${ }^{11}$.

Por otro lado, las garantías básicas del debido proceso incluyen el derecho de las partes a ser juzgado por autoridad competente. Según el artículo 76 numeral 7 literal k) de la Constitución, el derecho al debido proceso incluye el derecho a "[s]er juzgado

\footnotetext{
5. B. Cremades, "El Arbitraje en la Doctrina Constitucional Española", Lima Arbitration, No. 1, 2006, p. 186.

6. Tribunal Superior de Bogotá, Causa No. 11001220300020070038601, 29/11/2007.

7. LAM, N. 1, Art. 31

8. C. Coronel, “Arbitraje y Procedimiento”, Iuris Dictio Revista de Derecho, Vol. 7, 2007, p. 39.

9. Constitución de la República del Ecuador, Art. 76(7)(m), RO No. 449, 20/10/2008.

10. Corte Constitucional del Ecuador, Caso No. 007-16-SCN-CC, 28/10/2016.

11. LAM, N. 1, Art. 31.
} 
por una jueza o juez independiente, imparcial y competente $[. . .]^{\prime \prime}$ (énfasis añadido) ${ }^{12}$.

Aquello también es reconocido por sistemas internacionales. El Pacto Internacional de Derechos Civiles y Políticos en su artículo 14 establece el "derecho a ser oída públicamente y con las debidas garantías por un tribunal competente, independiente e imparcial" (énfasis añadido $)^{13}$. Asimismo, este derecho es reconocido en el artículo 8 de la Convención Americana de Derechos Humanos ${ }^{14}$. El ordenamiento jurídico exige que toda controversia sea resuelta por una autoridad competente, ya sea en vía ordinaria o en vía arbitral, las partes gozan de esta protección y de la facultad de solicitar una segunda revisión de la competencia del tribunal arbitral.

En conclusión, a pesar que los árbitros no son jueces ordinarios, toman decisiones impartiendo justicia ${ }^{15}$. De violarse normas del debido proceso en cualquier etapa del procedimiento arbitral, como la incompetencia de la autoridad que resuelve la disputa, las partes podrán activar la vía de control in procedendo; es decir, la acción de nulidad de laudo arbitral.

\section{LAS CAUSAles De NUlidad Del LAUdo ARBitRal EN EL ECUADOR}

La acción de nulidad del laudo arbitral tiene su fundamento en la desconfianza que tiene el Estado en un mecanismo privado de solución de conflictos ${ }^{16}$. Por ello, las causales de nulidad buscan proteger bienes jurídicos de tal importancia que ameritan una revisión por parte de un órgano jurisdiccional, dentro de una institución completamente autónoma que es el arbitraje ${ }^{17}$.

12. Constitución de la República del Ecuador, N. 9, Art. 76 (7)(k).

13. Pacto Internacional de Derechos Civiles y Políticos (1966), Art. 14.

14. Convención Americana sobre Derechos Humanos (1969), Art. 8.

15. Código Orgánico de la Función Judicial, N. 5.

16. F. GonZÁlez de Cossío, "Orden Público y Arbitrabilidad", Revista Internacional de Arbitraje, No. 9 , 2008, p. 10.

17. M. VÁsQUEZ, "Comprensión del principio 'competencia-competencia' y configuración de la nulidad o ineficacia del acuerdo arbitral”, Revista chilena de derecho privado, No. 15, 2010, pp. 181-196. 
Las causales previstas en la LAM son:

a) No se haya citado legalmente con la demanda y el juicio se ha seguido y terminado en rebeldía. Será preciso que la falta de citación haya impedido que el demandado deduzca sus excepciones o haga valer sus derechos y, además, que el demandado reclame por tal omisión al tiempo de intervenir en la controversia;

b) No se haya notificado a una de las partes con las providencias del tribunal y este hecho impida o limite el derecho de defensa de la parte;

c) Cuando no se hubiere convocado, no se hubiere notificado la convocatoria, o luego de convocada no se hubiere practicado las pruebas, a pesar de la existencia de hechos que deban justificarse;

d) El laudo se refiera a cuestiones no sometidas al arbitraje o conceda más allá de lo reclamado; $\mathrm{o}$

e) Cuando se hayan violado los procedimientos previstos por esta Ley o por las partes para designar árbitros o constituir el tribunal arbitral ${ }^{18}$.

No es objeto de este estudio, el análisis profundo de cada una de las causales. Sin embargo, es importante resaltar las siguientes conclusiones: (i) las tres primeras causales son una manifestación del interés del Estado del derecho a la defensa; (ii) la cuarta causal tiene dos partes importantes. Primero, la nulidad que puede generar los vicios de incongruencia en el laudo arbitral. Segundo, la interpretación de la expresión "cuestiones no sometidas a arbitraje" como una causal de incompetencia respecto a la voluntad. Esta causal será estudiada a fondo en la sección 4.3 del presente estudio.

Finalmente, (iii) la quinta causal se refiere a cuestiones procedimentales de la conformación del tribunal arbitral. Esta causal no busca atacar la competencia del tribunal, ni la validez o ejecutabilidad del convenio arbitral ${ }^{19}$.

18. LAM, N. 1, Art. 31.

19. Corte Provincial de Pichincha, Causa No. 17100-2014-0010, 07/08/2015. 


\section{LOS CRITERIOS DE COMPETENCIA EN UN PROCESO ARBITRAL}

El Código Orgánico General de Procesos (COGEP) considera la competencia del juzgador como una solemnidad sustancial común a todos los procesos ${ }^{20}$. Expresamente, el artículo 112, capítulo IX, sobre Nulidad de Sentencia, establece como causal de nulidad la falta de jurisdicción o competencia del juzgador ${ }^{21}$. Además, en el artículo 153 numeral 1 de la norma mencionada establece como excepción previa la incompetencia del juzgador ${ }^{22}$. La mera duda sobre la competencia del juzgador se tramita por los llamados juicios de competencia, previstos en los artículos 14 y 15 del $\mathrm{COGEP}^{23}$. Así, la competencia es fundamental en un proceso judicial.

Por otro lado, en arbitraje internacional también es indispensable el análisis de la competencia del tribunal. La doctrina lo denomina "laudo de competencia"24; el cual está destinado a la resolución de cuestiones incidentales del proceso. Se trata que el tribunal arbitral deberá pronunciarse sobre el alcance de su mandato y de sus atribucione ${ }^{25}$. En el arbitraje local ecuatoriano, el momento procesal para análisis la competencia del árbitro se realiza en una audiencia de sustanciación, según el artículo 22 de la LAM ${ }^{26}$.

Cabe recalcar que los criterios de valoración en juicio de competencia en sede judicial son distintos a aquellos aplicables en sede arbitral. La competencia de los jueces ordinarios se determina en razón a la persona, materia, territorio y grado. Ello conforme el artículo 156 del Código Orgánico de la Función Judicial del Ecuador ${ }^{27}$. El análisis de estos criterios no requiere una interpretación extensiva de la ley, basta subsumir los hechos a los presupuestos de la norma. Por otro lado, los criterios que determinan la competencia de los árbitros giran en torno a verificar: (i) la ar-

\footnotetext{
20. Código Orgánico General de Procesos (COGEP), Art. 107, RO Sup. No. 506, 22/5/2015.

21. COGEP, N. 20, Art. 112.

22. COGEP, N. 20, Art. 153.

23. COGEP, N. 20, Arts. 14 y 15.

24. F. GonZÁlez de Cossío, Arbitraje, Porrúa, 2008.

25. R. De Pina, Instituciones de Derecho Procesal Civil, Porrúa, 1997.

26. LAM, N. 1, Art. 22

27. Código Orgánico de la Función Judicial, N. 5, Art. 156.
} 
bitrabilidad de la materia, (ii) las personas que manifestaron la voluntad de arbitrar y (iii) la voluntad de las partes respecto al ámbito y alcance de la cláusula arbitral ${ }^{28}$.

Los criterios mencionados son susceptibles de amplias interpretaciones por parte de los árbitros que conocen la causa. En las siguientes secciones se procede a analizar la competencia del tribunal arbitral en razón de tres parámetros: ratione materiae, ratione personae y ratione voluntatis.

\subsection{Competencia ratione materiae}

La LAM en su artículo 1 establece que: “[e]l sistema arbitral es un mecanismo alternativo de solución de conflictos al cual las partes pueden someter de mutuo acuerdo, las controversias susceptibles de transacción [...]" (énfasis añadido) ${ }^{29}$. Para determinar que controversias son susceptibles de transacción, es necesario remitirse al artículo 8 del Código Civil Ecuatoriano (en adelante, Código Civil) que prescribe "a nadie puede impedirse la acción que no esté prohibida por la ley"30. La interpretación de esta norma, según PARRAGUEZ y DARQUEA, es que: "será transigible todo aquello que no haya sido declarado expresamente como no transigible por ley"31. No obstante, la ley no regula todos los supuestos que no se puede transigir; $y$, si lo regula, esta no suele ser clara. Aquello ha generado puntos de controversia, por ejemplo, en materia laboral ${ }^{32}$.

Ante la ausencia de regularidad o claridad por la ley, se ha tomado el criterio de orden público para determinar la arbitrabilidad de la materia ${ }^{33}$. A pesar que existe referencia expresa al

28. S. RodRíGUEZ, "El sistema arbitral del CIADI". Anuario Mexicano de Derecho Internacional, Vol. VII, 2006, p. 783.

29. LAM, N. 1, Art. 1.

30. Código Civil, Art. 8, RO Sup. No. 46, 24/06/2005.

31. L. Parraguez y J. Darquea, "La Arbitrabilidad del daño moral”, Revista Ecuatoriana de Arbitraje, No. 8, 2016, p. 97.

32. M. JARA, "Reflexiones sobre el arbitraje como mecanismo alternativo para la solución de conflictos individuales de trabajo", Revista de Derecho, No. 24, 2015, p. 40.

33. R. CAIVAno, "Arbitrabilidad y Orden Público", Foro Jurídico, No. 12, 2013, p. 65. 
orden público en varios cuerpos normativos como la Ley Modelo de la Comisión de las Naciones Unidas para el Derecho Mercantil Internacional ${ }^{34}$ y Ley de Arbitraje del Perú ${ }^{35}$, no se ha logrado un consenso respecto a su definición. Entre los intentos de definirlo, se puede destacar al orden público como "aquellas nociones de moralidad y justicia dentro del sistema jurídico de cada estado"36. El orden público también es considerado como la prevalencia del interés general sobre el individual ${ }^{37}$. La definición de orden público es amplia, por lo que se encuentra sujeta a extensivas interpretaciones. La Corte de Apelaciones del Distrito de Columbia presupone que usar el criterio de orden público es un estándar alto y rara vez alcanzado ${ }^{38}$.

Así, se demuestra que existe un área gris cuando el árbitro realiza una valoración de conceptos abstractos para determinar su competencia ratione materiae ¿Podrían cometerse errores en este ejercicio de valoración? Sin duda alguna.

\subsection{Competencia ratione personae}

El arbitraje tiene su esencia en la autonomía de la voluntad de las partes que se expresa en el convenio arbitral ${ }^{39}$. La competencia en razón de la persona encuentra relevancia en cuanto a la oponibilidad de los efectos de la cláusula arbitral frente a un tercero $^{40}$. El principio de relatividad de los negocios jurídicos determina que los efectos de un negocio surgen únicamente entre las partes $^{41}$. Sobre este principio, el artículo 1561 del Código Civil establece que: "todo contrato legalmente celebrado es una ley para

34. Ley Modelo de la CNUDMI, Art. 34.

35. Ley de Arbitraje del Perú, Art. 63, Decreto Legislativo No. 1071, 9/08/2010.

36. F. GonZÁlez de Cossío, N. 24, p. 61.

37. C. CARABIBER, L'arbitrage international de Droit Privé, LGDJ, 1960, p. 119.

38. Tribunal de Apelaciones de los Estados Unidos del Circuito del Distrito de Columbia, Termorio S.A. E.S.P. and LeaseCo Group, LLC c. Electranta S.P. y otros, Caso No. 06-7058, 25/05/2007.

39. R. Herrera, "La autonomía de la voluntad en el arbitraje y en la mediación. Jurisprudencia constitucional española y experiencias en el ámbito del consumo", Revista de Derecho, Vol. XXV, 2012, p. 180.

40. A. Villalobos y M. París, "La Cláusula Arbitral a Partes no Signatarias", Revista de ciencias jurídicas, No. 131, 2013, p. 21.

41. H. GARCíA, "Partes no signatarias del convenio arbitral: entre la realidad económica y la ficción jurídica", Revista Ecuatoriana de Arbitraje, Vol. 15, 2013, p. 85. 
los contratantes, y no puede ser invalidado sino por su consentimiento mutuo o por causas legales" ${ }^{\prime 2}$.

Cabe recalcar que "[c]ada parte puede ser una o muchas personas" ${ }^{\prime 4}$. Es decir, una parte puede ser varias personas que busquen la consecución de un mismo interés. Además, una parte puede ser formal o material. La parte formal es quien expresa la voluntad del negocio jurídico; mientras que la parte sustancial es titular de los intereses de la relación jurídica ${ }^{44}$.

De esta manera, se someten a arbitraje no sólo quien suscribe, sino quien tiene intereses en la relación jurídica. ¿Cómo conocer quién tiene dicho interés para ser considerado como parte? Existen varias teorías doctrinarias que explican la intervención de una parte no signataria, tal como la teoría del grupo de sociedades, la incorporación por referencia, la relación de agencia, teoría del alter ego, entre otras ${ }^{45}$. Todas ellas permanecen en constante discusión doctrinaria, y las decisiones han dependido de la interpretación amplia o restringida de los tribunales arbitrales de la teoría de partes no signatarios. Por ejemplo, en el caso Dow Chemical c. Isover Saint Gobain el tribunal mencionó que la cláusula arbitral aceptada por una sociedad obliga a las demás compañías del grupo económico ${ }^{46}$. No obstante, en el caso 6673 de la CCI, el tribunal rechazó esta teoría ${ }^{47}$.

Analizar la competencia en razón de la persona es analizar la aplicabilidad o no de teorías puramente doctrinarias que continúan en desarrollo. Por ende, la ambigüedad al determinar la competencia en razón de la persona ha sido una puerta abierta para que tribunales decidan conforme a su criterio, pues no existe norma expresa a la cual referirse. Una vez más, ¿podrían cometerse errores en este ejercicio de valoración de competencia que recae en los árbitros?

42. Código Civil, N. 30, Art. 1561.

43. Código Civil, N. 30, Art. 1454.

44. H. García, N. 41, p. 87.

45. Ídem, pp. 96-98.

46. Tribunal de Arbitraje del Centro de Comercio Internacional, Dow Chemicals c. Isover Saint Gobain, Caso No. 4131, 1982.

47. Tribunal de Arbitraje del Centro de Comercio Internacional, Caso No. 6673, 1992. 


\subsection{Competencia ratione voluntatis}

En primer lugar, la competencia en razón de la voluntad se encuentra relacionada con el contenido y alcance de la cláusula arbitral, toda vez que en ella se define el ámbito de la disputa sometida a arbitraje ${ }^{48}$. Como afirma VIDAL, es necesario observar la cláusula arbitral para determinar los límites sobre los cuáles el árbitro tiene competencia ${ }^{49}$.

En segundo lugar, dentro del ámbito de la cláusula arbitral, es necesario analizar si existen requisitos o condiciones para el perfeccionamiento de la voluntad de someterse a arbitraje $\mathrm{e}^{50}$. A modo de ejemplo, los cooling off periods o waiting periods obliga a las partes a negociar en un periodo de tiempo determinado antes de acudir a la justicia arbitral ${ }^{51}$. En consecuencia, es responsabilidad de los árbitros verificar que la voluntad de las partes no se encuentre condicionada o pendiente antes de declararse competente para conocer la causa.

Aterrizando a la normativa nacional, la causal d) del artículo 31 de la LAM hace referencia a las cuestiones no sometidas a arbitraje o que concedan más allá de lo reclamado ${ }^{52}$. La primera parte de esta norma tiene que ver con arbitrabilidad subjetiva; es decir, con la competencia ratione voluntatis. Mientras que la segunda parte trata de vicios de incongruencia que no es tema de discusión de este artículo.

En un proceso de acción de nulidad bajo esta causal, el juez deberá declarar nulo todo aquello que verse sobre ámbitos o efectos que las partes no sometieron a arbitraje, sin analizar el fondo. De esta manera, se evidencia que la normativa ecuatoriana recoge una causal referente a la falta de competencia en razón de la voluntad.

48. J. SiQueIros, "El Alcance (Rationae Materiae Y Ratione Personae) del Acuerdo de Arbitraje en Derecho Mexicano", Anuario Mexicano de Derecho Internacional, Vol. 5, 2005, p. 25.

49. R. VIDAL, "Alcances de la Ejecución del Laudo Arbitral”, R.E.D.S, No. 11, 2017, p. 85.

50. R. Nieto, "La paradoja del auge del Arbitraje Internacional de Inversión, en Arbitraje Internacional”, Tensiones Actuales, 2007, p. 35.

51. J. Robledo y R. RinCÓN, "El arbitraje y el gobierno corporativo", Perspectiva, 2006, p. 42.

52. LAM, N. 2, Art. 31. 
Ahora, para realizar un análisis completo sobre el tema es importante comparar la legislación arbitral ecuatoriana con legislaciones arbitrales extranjeras, en específico el caso de Colombia y Chile.

\section{LA INCOMPETENCIA COMO CAUSAL DE NULIDAD DEL LAUDO EN EL DERECHO COMPARADO}

\subsection{Breve análisis del caso colombiano}

El artículo 41 numeral 1 de la Ley 1563 de 2012 de Colombia establece como una causal de nulidad "[1]a inexistencia, invalidez absoluta o inoponibilidad del pacto arbitral" ${ }^{153}$. La Corte Constitucional de Colombia hace énfasis en que la inoponibilidad del pacto arbitral como causal de nulidad del laudo no constaba como causal en el anterior estatuto, concluyendo que:

Ahora bien, teniendo en cuenta que el pacto arbitral es un negocio jurídico, es consecuencia obligada que en principio él sólo produce efectos jurídicos frente a las partes que lo celebran y no a quienes no han sido parte en él, razón por la cual tal negocio, por regla general, es inoponible frente a estos ${ }^{54}$.

Es anulable un laudo arbitral que produzca efectos jurídicos frente a personas ajenas al negocio, ya sea creando, modificando o extinguiendo derechos $\mathrm{u}$ obligaciones de estos ${ }^{55}$. Como consecuencia se tipifica expresamente la incompetencia del tribunal arbitral en razón de la persona.

Luego, el artículo 41 numeral 2 de la Ley 1563 de 2012 establece como causal de nulidad "[1]a caducidad de la acción, la falta de jurisdicción o de competencia" (énfasis añadido) ${ }^{56}$. En un recurso

53. Ley 1563 por medio del cual se expide el Estatuto de Arbitraje Nacional e Internacional y se dictan otras disposiciones, Art. 41, Diario Oficial 48489, 12/07/2012.

54. Corte Constitucional de Colombia, Caso T-511/11, 16/02/2009.

55. Ibídem.

56. Consejo de Estado. Sala de lo Contencioso, Causa No. 11001-03-26-000-2014-00162-00(52556), 23/04/2015. 
de nulidad del laudo arbitral entre EMGESA S.A. c. Sociedad Hotelera Tequendama S.A., la Sala de lo Contencioso Administrativo de Colombia, realiza una distinción clara respecto de la falta de jurisdicción arbitral y la falta de competencia arbitral:

Se entiende que la jurisdicción es la función pública de administrar justicia, esto es, aplicar la ley a un determinado conflicto y la competencia es la facultad que se le otorga a determinados órganos públicos o particulares para ejercer dicha función sobre ciertos asuntos o negocios determinados, es decir, ésta última es una parte de la jurisdicción ${ }^{57}$.

Además, en el caso mencionado se declara que habrá carencia de jurisdicción cuando el convenio arbitral no existe, o cuando el asunto que se somete a arbitraje no está autorizado por la ley para ser resuelto en esta sede. Mientras que, habrá carencia de competencia del tribunal arbitral, con base al principio de habilitación, cuando este se pronuncie sobre asuntos que por voluntad de las partes no se encontraban sometidos a su decisión ${ }^{58}$.

A diferencia del Ecuador, en Colombia existe una causal expresa por falta de competencia y falta de jurisdicción del tribunal arbitral. Dicha causal abarca la competencia en razón de la materia susceptible de arbitraje por ley y orden público, y la competencia en razón de la voluntad expresada en el convenio arbitral. De esta forma, protegen el derecho al juez natural, y al principio de habilitación del árbitro por la voluntad.

\subsection{La incompetencia como causal en Chile}

En Chile, la Ley de Arbitraje en su capítulo VII, artículo 34, enumera las causales de impugnación del laudo, estableciendo la nulidad como único recurso contra un laudo arbitral. En el numeral 2 literal a) primer inciso del mismo artículo, se establece que podrá pedirse nulidad del laudo arbitral cuando una de las partes en el acuerdo arbitral está afectada por alguna incapaci-

57. Ibídem.

58. Ibídem. 
dad. A diferencia del Ecuador, Chile hace referencia a la condición de las partes como motivo para declarar nulo el laudo arbitral. A pesar de que podría plantearse como excepción previa ${ }^{59}$.

En el mismo numeral, literal a) inciso tercero, se establece que podrá pedirse nulidad si se prueba:

Que el laudo se refiere a una controversia no prevista en el acuerdo de arbitraje o contiene decisiones que exceden los términos del acuerdo de arbitraje; no obstante, si las disposiciones del laudo que se refieren a las cuestiones sometidas al arbitraje pueden separarse de las que no lo están, sólo se podrán anular estas últimas (énfasis añadido) ${ }^{60}$.

Nótese que, este inciso se refiere expresamente a la voluntad de las partes, o arbitrabilidad subjetiva. Luego, en el literal b) del mismo artículo, establece que podrá pedirse nulidad del laudo cuando el tribunal compruebe que: (i) según la ley chilena el objeto de la controversia no es susceptible de arbitraje y (ii) que el laudo sea contrario al orden público de Chile ${ }^{61}$. Siendo estas dos últimas causales expresiones de la arbitrabilidad en razón de la materia. A diferencia del Ecuador, Chile plantea causales específicas para revisar la competencia de los árbitros en razón de la voluntad de las partes y la materia de la controversia.

Además, en Chile no se hace referencia a una acción sino a un recurso de nulidad que se plantea hasta tres meses contados desde la fecha de recepción del laudo. Este recurso se plantea ante el Presidente de la Corte de Apelaciones respectiva y no se suspende la actuación arbitral. Las partes tienen la posibilidad de requerir a los árbitros que emita un laudo adicional respecto de reclamaciones formuladas en actuaciones arbitrales. En este último caso, tendrán las partes treinta días a partir de la recepción del laudo ${ }^{62}$.

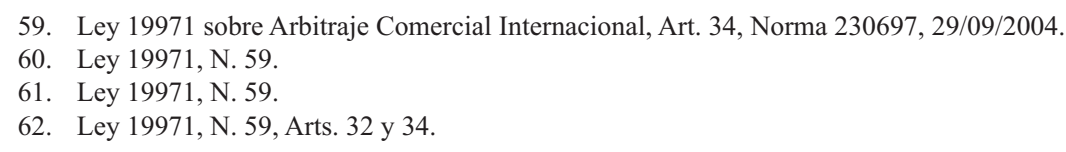




\section{6. ¿SE REQUIERE LA CAUSAL DE NULIDAD POR FALTA DE COMPETENCIA DEL TRIBUNAL ARBITRAL EN EL ECUADOR?}

En Ecuador, a través de la vía ordinaria puede solicitarse la nulidad del laudo arbitral por incompetencia del árbitro por cuestiones no sometidas a arbitraje. Es decir, por contrariar la voluntad de la partes expresada en el convenio arbitral ${ }^{63}$. Sin embargo, no existe causal de nulidad del laudo por falta de competencia en razón de la materia y persona. En dichos casos, la parte agraviada solo podrá recurrir a la Corte Constitucional mediante acción extraordinaria de protección ${ }^{64}$.

Una vez que se propone la acción extraordinaria de protección, la justicia constitucional puede conocer sobre laudos arbitrales que hayan violado derechos constitucionales del debido proceso $^{65}$. Sin embargo, esta acción es de carácter extraordinario y debería ser invocado si no existe otro medio para resarcir el derecho violentado ${ }^{66}$. No se justifica recurrir a la justicia constitucional para resolver sobre la competencia de un tribunal arbitral, si existe un procedimiento que precautela el debido proceso, incluyéndose el derecho a un juez competente, como es la acción de nulidad.

En efecto, la discusión recae en la posibilidad de incluir la falta de competencia del tribunal como causal de nulidad del laudo. Existen argumentos a favor y en contra de esta propuesta.

En primer lugar, se suscita una presunta vulneración al principio kompetenz-kompetenz. En un inicio se consideraba que el único que podía conocer sobre su propia competencia era el árbitro $^{67}$. Sin embargo, esta discusión ha sido superada. Desde una visión moderna, el principio kompetenz-kompetenz concede prefe-

63. LAM, N. 1, Art. 31(d).

64. Corte Constitucional, Caso No. 113-15-SEP-CC, 08/04/2015.

65. Corte Constitucional, Caso No. 0006-10-SEP-CC, 24/02/2010.

66. A. CABO et al., "Investigación jurídica comparada", Boletín No. 390 del Centro de difusión y estudios del derecho constitucional, 2016, p. 1.

67. E. SiLVA, "Breves observaciones sobre el principio Kompetenz-Kompetenz", Universidad del Rosario, 2005 , p. 580 . 
rencia temporal al árbitro para pronunciarse sobre su propia competencia, más no exclusividad para hacerlo ${ }^{68}$. La posibilidad de analizar la competencia del tribunal por segunda vez, protege el derecho a tutela judicial efectiva y el derecho a ser juzgado por un juez competente, sin menoscabar la potestad del árbitro de decidir sobre su propia competencia.

En segundo lugar, existe una supuesta afectación a la naturaleza del arbitraje por revisarse la competencia del tribunal arbitral en sede judicial. En realidad, sucede todo lo contrario ya que constituiría un refuerzo a la legalidad de los deberes y atribuciones de los árbitros, y a la confianza del sistema arbitral. Esto en virtud que se garantiza la protección de derechos fundamentales del debido proceso, doble conforme, tutela judicial efectiva y a ser juzgado por un juez competente. Derechos que deben ser respetados por cualquier sistema de administración de justicia.

Incluir causales expresas de nulidad del laudo arbitral por falta de competencia del tribunal garantizará: (i) motivación en cada resolución o decisión por parte de los árbitros respecto de su competencia; (ii) unidad y concordancia entre laudos arbitrales respecto de los parámetros de competencia de los árbitros en razón de la materia, voluntad y personas; (iii) seguridad jurídica y confianza en el sistema arbitral; (iv) protección de principios y garantías básicas encaminadas a evitar la indefensión; y, (v) se obtienen precedentes sobre conceptos indeterminados como orden público, transigibilidad, arbitrabilidad, entre otros.

El control de la competencia a través de la acción de nulidad, hará que los árbitros analicen a profundidad su competencia bajo distintos parámetros, teorías doctrinarias, principios y garantías básicas del debido proceso. De esta manera, habrá una mejora del sistema de justicia en general. No solo deberá estar preparado el tribunal arbitral a la hora de motivar una decisión sobre su competencia, sino también jueces ordinarios que podrían conocer el recurso de nulidad. 


\section{Obstáculos de la causal por falta de COMPe- TENCIA EN LA ACCIÓN DE NULIDAD}

La crítica principal es la desnaturalización del arbitraje. Entre las características del arbitraje se extrae que es un proceso rápido y eficiente ${ }^{69}$ al que las partes acuden para obtener una decisión final y vinculante. Abrir la posibilidad que se revise la competencia del tribunal arbitral en una segunda instancia vulnera la celeridad con que opera el arbitraje. Además, se ocasiona un daño directo a las partes por la pérdida de tiempo y dinero por acudir a la justicia ordinaria. Bajo la misma noción, someter la revisión de competencia del árbitro a jurisdicción ordinaria es una violación a la autonomía de la voluntad de las partes. Dicha voluntad buscaba, en principio, someter sus disputas a arbitraje evitando el formalismo y la ineficiencia del proceso judicial ${ }^{70}$.

Ahora, aumentar una causal de nulidad del laudo arbitral por incompetencia del tribunal sería dar paso a incertidumbre e inseguridad jurídica. Toda vez que quedará en manos de jueces ordinarios la aplicación de principios de un sistema autónomo y auto contenido, como es el sistema arbitral. En palabras de CoRONEL, a pesar de la flexibilidad que pueda ofrecer el arbitraje, los jueces y abogados en la práctica siguen aplicando formalismos antagónicos que de nada sirven en muchos de los casos, más que para demorar el proceso ${ }^{71}$. Si esto ya sucede en el arbitraje, más aun cuando los jueces revisan un laudo arbitral.

En caso que se declare la nulidad de laudo por incompetencia, las partes habrán pasado por: (i) un proceso arbitral; (ii) por una acción de nulidad; y, (iii) una vez anulado el proceso arbitral, pasarían por un nuevo proceso para obtener una decisión de fondo. ¿Es posible garantizar la celeridad con tres procesos accionados? ¿Afecta esto a la tutela judicial efectiva? Al parecer, sí.

69. J. M. RocA, Arbitraje e instituciones arbitrales, Editor J. M. Bosch, 1991, p. 2.

70. B. Benson, International Economic Law and Commercial Arbitration, Economic Analysis of Law: A European Perspective, Edward Elgar Publisher, 2000, pp. 73-84.

71. C. Coronel, N. 8, p. 40. 
Así, es importante cuestionar si la cultura jurídica de los jueces ordinarios en Ecuador es suficiente para abordar parámetros de competencia arbitral en razón de la materia, persona y voluntad. En el país ha existido gran controversia sobre la falta de independencia de los jueces y la corrupción del sistema judicial ${ }^{72}$. Es evidente, que uno de los principales retos para introducir la incompetencia como causal de nulidad será crear un proceso idóneo, no gravoso, rápido, eficaz, independiente y transparente. Garantizar un derecho no debe ser razón para suprimir otros.

\section{Conclusiones}

i. El derecho a la revisión de la competencia del tribunal arbitral es una expresión de la garantía básica del debido proceso. El arbitraje reconocido como una forma de ejercer jurisdicción, se desenvuelve en el marco de los principios del derecho procesal constitucional que reconoce la ley. Por lo tanto, el derecho al doble conforme y el derecho a ser juzgado por autoridad competente, deberán ser respetados y garantizados tanto por jueces y árbitros, en todas las etapas procesales.

ii. En sistemas jurídicos extranjeros existe la falta de competencia de los árbitros como causal de nulidad del laudo. En el caso de Colombia, la causal es amplia y abarca parámetros de competencia en razón de la materia, personas y voluntad. Mientras que en el caso de Chile, se señalan presupuestos que contienen cada uno de los criterios de competencia de los árbitros por separado.

iii. A diferencia del Ecuador, el artículo 31 de la LAM hace referencia a la competencia en razón de la voluntad ya que solo se refiere a cuestiones no sometidas a arbitraje. Por lo que se deja de lado la incompetencia en razón de la materia y persona. Así, las partes no podrán impugnar aquellas valoraciones de orden público, transigibilidad de la materia ni la aplicación de teorías de partes no signatarias. Actualmente,

72. S. Basabe-Serrano, "Explicando la corrupción judicial en las cortes intermedias e inferiores de Chile, Perú y Ecuador", Perfiles Latinoamericanos, No. 2, 2013, pp. 92-94. 
la única vía posible de revisión respecto a estos dos criterios, es la vía constitucional mediante acción de protección.

iv. Implementar una causal general por falta de competencia del tribunal arbitral es factible en la medida en que los jueces conozcan qué criterios deberán valorar para declarar la competencia del tribunal arbitral, estos son: ratio materiae, ratio voluntatis, y ratio personae. Con ello, la interpretación de principios del debido proceso deberá ser sistemática, armónica, coherente y restringida en concordancia con la constitución y la ley. Cabe recalcar que, como requisito al planteamiento de dicha causal, se debe interponer como excepción previa la falta de competencia del árbitro en audiencia de sustanciación, tal como sucede en otros países. De esta forma se garantiza la buena fe procesal, celeridad, economía procesal y el principio de preclusión.

v. Incluir la causal de nulidad del laudo por falta de competencia del árbitro que abarque los tres parámetros, generará que los árbitros analicen con mayor profundidad su competencia y decidan motivadamente. A su vez, los jueces requerirán mayor preparación para no cometer arbitrariedad. Por ende, la causal propuesta, a más de evitar indefensión por errores arbitrales, apunta a mejorar la cultura jurídica del Ecuador y a brindar confianza en el sistema arbitral. 